\title{
The Effect of Monomers on the Recognition Properties of Molecularly Imprinted Beads for Proto-hypericin and Proto-pseudohypericin
}

\section{ANA-MIHAELA (FLOREA) GAVRILA ${ }^{1 \#, ~ T A N T A-V E R O N A ~ I O R D A C H E ~}{ }^{1 \#, ~}$ CATHERINE BRANGER ${ }^{2}$, HUGUES BRISSET ${ }^{2}$, KATRI LAATIKAINEN ${ }^{3}$, ANA LORENA CIURLICA ${ }^{1}$, ANAMARIA ZAHARIA ${ }^{1}$, ANITA LAURA RADU ${ }^{1}$, ALINA-ELENA COMAN ${ }^{1}$, SIMONA FLOR ${ }^{4}$, ANDREI SARBU ${ }^{1 *}$}

${ }^{1}$ National Research and Development Institute for Chemistry and Petrochemistry ICECHIM, Advanced Polymer Materials and Polymer Recycling, 202 Splaiul Independentei, 060021, Bucharest, Romania

${ }^{2}$ Laboratoire MAPIEM, EA 4323, Universite de Toulon, CS 60584, 83041 Toulon Cedex 9, France

${ }^{3}$ Lappeenranta-Lahti University of Technology LUT, Laboratory of Computational and Process Engineering, P.O. Box 20, FI-53851 Lappeenranta, Finland

${ }^{4}$ University Politehnica of Bucharest, The Faculty of Applied Chemistry and Material Science, Bioresources and Polymer Science Department, 1-7 Polizu Str., 011061, Bucharest, Romania

\begin{abstract}
Molecularly imprinted polymer (MIP) beads for proto-hypericin recognition were prepared by suspension polymerization. In order to study the impact of monomers on the MIPs properties, various monomers such as acrylic acid (AA), hydroxyethyl methacrylate (HEMA), methacrylic acid (MAA) and itaconic acid (IA) in their combinations were crosslinked with ethylene glycol dimethacrylate (EDMA) in the presence of a complex phyto-extract template derived from Hypericum perforatum L. The synthesized MIPs and corresponding non-imprinted polymers NIPs were characterized by infrared spectroscopy analysis, morphology and thermogravimetric analysis. Highperformance liquid chromatography combined with $U V$-Visible spectroscopy, used to investigate the recognition properties of the MIPs for various naphthodianthrones, pointed out that the MIP IA-AA system seemed to be the most adequate for favoring quantitative rebinding of proto-hypericin and proto-pseudohypericin against competitors with similar structures, like hypericin and pseudohypericin, which are usually present in high quantities in the primary Hypericum perforatum L. phytoextracts.
\end{abstract}

Keywords: Molecularly imprinted beads; suspension polymerization; proto-hypericin; proto-pseudohypericin; Hypericum perforatum $L$.

\section{Introduction}

Nowadays, Hypericum perforatum, commonly known as St. John's Wort (SJW) and member of the Hypericaceae family is one of the top-selling medicinal herbs with worldwide distribution [1,2]. It has been used as an antidepressant herbal drug [3,4] and it has also been traditionally known as an external remedy for minor burns, skin inflammation, wounds and ulcers. The most studied compounds present in SJW are hyperforin, hypericins and flavonoids, which are assumed to be responsible for the activity of the extract in the treatment of wounds and scars. The hypericins exhibit potent pharmacological effects that include antiretroviral activity against HIV infection and hepatitis C [7] as well as inhibition of protein kinase C [8]. Recently, hypericins have gained increasing interest due to their cytotoxic and pro-apoptotic effects against tumor cell lines that proved to be excellent chemoprotective agents [9].

\footnotetext{
*email: andr.sarbu@gmail.com "Authors with equal contribution
} 
Hypericins or naphthodianthrones (NTs) include hypericin, pseudohypericin and their biosynthetic precursors, i.e. proto-hypericin and proto-pseudohypericin. The biosynthetic precursors are usually found in very low quantities in the primary extracts of Hypericum perforatum L. [5,6]. Hence, the greatest interest in SJW extracts was attributed to hypericin $(\mathrm{H})$ and its structural analog pseudohypericin (PH), because of their higher stability and bioavailability [10]. Several methods were described in the literature for the isolation and purification of hypericins from Hypericum species, which mainly used preparative High-Performance Liquid Chromatography (HPLC), Thin-Layer Chromatography (TLC), gas chromatography and GC-MS, mass spectrometry and associated hyphenated techniques, Solvent-Free Microwave Extraction (SFME) of oil and also Near-Infrared Spectroscopy (NIRS) [11-13].

At present, there are very few reports in the literature investigating the pharmacological effect of the biosynthetic precursors proto-hypericin and proto-pseudohypericin, due to their low bioavailability and stability to light. Hence, this study proposes the use of a molecular imprinting technique to produce selective beads for the recognition of the biosynthetic precursors, i.e. proto-hypericin and proto-pseudohypericin, and serve as separation tools for these two particular compounds.

Molecular imprinting is a powerful and convenient method to prepare polymeric materials with antibody-like recognition properties [14,15]. It usually includes a crosslinking polymerization process in the presence of a template molecule, which is extracted afterwards to generate imprinted cavities in the polymer matrix. Thus, the molecular information becomes complementary to the template in both topography and chemical functionality, with a high degree of selectivity. The resulted molecularly imprinted polymers (MIPs) are robust, exhibiting resistance to elevated temperatures and pressures, inertness to acids, bases and organic solvents, low production cost and ease of preparation as well as excellent recognition properties. These attributes make MIPs ideal for extensive application in solidphase extraction, biosensors, membranes, electrochemical sensing receptors and explosives, and also in green technologies such as supercritical fluid or microwave methods [16-22].

Although several methods have been reported for the preparation of MIPs, the suspension polymerization method was first employed by our group to prepare MIP hollow beads using a methacrylic acid (MAA)-acrylonitrile (AN)-ethylene glycol dimethacrylate (EDMA) matrix for extracting $\mathrm{H}$ and $\mathrm{PH}$ from SJW phyto-extracts [23]. Cheng et al. [24] reported on the preparation of core-shell magnetic molecularly imprinted nanospheres towards hypericin (Fe3O4@PDA/Hyp NSs) via surface molecular imprinting techniques. The results pointed out slightly high adsorption capacities $(\mathrm{Q}=18.28 \mathrm{mg} / \mathrm{g})$ for $\mathrm{H}$ and high imprinting factors, near 8. Further on, Pei et al. [25] have explored the possibility of using two types of click reactions (azide-alkyne and thiol-yne) to synthesize molecularly imprinted nanospheres with hypericin as the template (MIP-NSHs). In this case, the adsorption capacity of the MIP-NSHs remained high, indicating good stability but the imprinting factors towards $\mathrm{H}$ were lower. Nevertheless, very few studies were found on the use of MIPs for the separation of the biosynthetic precursors, i.e. proto-hypericin and proto-pseudohypericin [24, 25].

Based on previous studies employed by our group, it was found that the nature of the polymer matrix has a significant influence upon the imprinting effect of the template, especially when the template is a secondary extract of naphthodianthrones $[23,20]$, containing at the same time hypericin and pseudohypericin, and traces of their biosynthetic precursors. Hence, by a fine tuning of monomer composition the resulted MIPs can recognize hypericin, pseudohypericin or their biosynthetic precursors. As a result, the present work describes a simple method on how to prepare MIP beads by suspension polymerization to recognize proto-hypericin (proto-H) and proto-pseudohypericin (proto$\mathrm{PH}$ ), using a concentrated extract of $0.029 \mathrm{wt} \%$ NTs (with traces of these biosynthetic precursors) as "phyto-template". In this respect, various potential monomers and their combinations were used to establish the optimum system, which can confer to the final MIP beads high adsorption capacities and specificity for proto-H and proto-PH. The molecular imprinting approach with a "phyto-template" was first described by our group [23, 20] and proved to deliver better results than the use of pure hypericin as template [26]. It is also worth mentioning the fact that this is the first study describing the molecular 
imprinting of polymers using a "phyto-template" with the aim of obtaining MIPs for the retention of proto-H and proto-PH.

\section{Materials and methods}

For beads preparation, the monomers, such as acrylic acid (AA, 98\%), methacrylic acid (MAA, 97\%), itaconic acid (IA, 98\%) and 2-hydroxyethyl methacrylate (HEMA, 99\%) were purchased from ACROS Organics and purified prior use by standard distillation procedures to remove inhibitors; with exception for IA. The crosslinker ethylene glycol dimethacrylate (EDMA, 99\%, Merck) and the suspension agent poly (vinyl alcohol) (PVA, hydrolysis degree 88\%, ACROS Organics) were used without further purification. The initiator 2,2'-Azobis (2-methylpropionitrile) (AIBN, ACROS Organics) was purified by recrystallization from ethanol. The reagents used for template removal, i.e. sodium hydroxide (NaOH- pellets) and hydrochloric acid $0.1 \mathrm{~N}(\mathrm{HCl}$, analytical grade) were purchased from Sigma-Aldrich. The saline agent sodium chloride $(\mathrm{NaCl})$ was dried under vacuum before use. The purified and concentrated hydro-alcoholic extract $(0.29 \mathrm{~g} / \mathrm{L} \mathrm{NTs}, 30 / 70$, v/v) from Hypericum perforatum L. (namely St. John's Wort flower) dried plant material was provided by Plantavorel S.A. (from Piatra Neamt, Romania) and used as NTs template. Hypericin (98\%, Tocris Bioscience, Bristol, U.K., H) and pseudohypericin ( $\geq 95 \%$ HPLC, Sigma-Aldrich, PH) standards were used as received. Ethanol (EtOH, 99.6\%) used for batch experiments was supplied by Chimopar. Deionized and distilled water was used for the polymer synthesis and for washing.

\section{Apparatus}

Scanning Electron Microscope (SEM) images of beads were recorded with a Supra40 VP (Gemini $\left.{ }^{\circledR}\right)$ equipped with a secondary electron detector (SE2). The samples were coated with gold to enhance their conductivity. Fourier Transformed-Infrared (FTIR) spectra were registered on Spectrometer (Thermo-Nicolet IS50) in the 400-4000 $\mathrm{cm}^{-1}$ range with $4 \mathrm{~cm}^{-1}$ resolution and 32 scans (ATR method). Thermal Gravimetric Analyses (TGA) were performed using TSD Q600 (No32) TA Instruments, under nitrogen atmosphere, at a constant heating rate of $20{ }^{\circ} \mathrm{C} / \mathrm{min}$ (temperature ranging from 25 to $900{ }^{\circ} \mathrm{C}$ ). Batch adsorption experiments were carried out using spectrophotometry (UV-vis Spectrometer Thermo Nicolet Evolution 500) in the 200-800 nm wavelength range and high-pressure liquid chromatography HPLC (Varian Prostar, Prostar 350 autosampler) equipped with a Mediterranean SEA C18, $5 \mu \mathrm{m} 15$ x $0.46 \mathrm{~cm}$ column (Teknokroma) and diode array detector (DAD).

\section{Preparation of beads by suspension polymerization}

Molecularly imprinted polymers (MIPs) and non-imprinted polymers (NIPs) were prepared using a single-pot aqueous suspension polymerization method pursuant to a previously described approach [23]. In a $250 \mathrm{~mL}$ round-bottom flask, the continuous phase was first prepared from $200 \mathrm{mg} / 200 \mathrm{mg}$ $\mathrm{PVA} / \mathrm{NaCl}$ dissolved in $48 \mathrm{~mL}$ deionised water (according to Table 1); the flask was then fitted with a mechanical stirrer, a nitrogen inlet and introduced in a thermostatic bath for 30 minutes at $70{ }^{\circ} \mathrm{C}$. The homogenous mixture was purged with nitrogen for $10 \mathrm{~min}$. In parallel, the dispersed organic phase, consisting of AIBN, EDMA, various monomers i.e. AA, HEMA, IA and MAA (ratios given in Table 1) and the "phyto-template" was homogenised at $200 \mathrm{rpm}$ in a separate flask. Finaly, the organic phase was gradually injected into the round-bottom flask containing the continuous phase, through a stopper, and kept at a constant stirring rate of $400 \mathrm{rpm}$. The polymerization process was carried out at $80{ }^{\circ} \mathrm{C}$ under stirring and nitrogen atmosphere. After $6 \mathrm{~h}$, the reaction was stopped and the obtained beads were filtered and washed with distilled water in order to remove the unreacted monomers and stabilizer. Non-imprinted polymers (NIPs) were prepared under the same conditions with the MIPs, but using only EtOH/ $\mathrm{H}_{2} \mathrm{O} 70 / 30 \%$ vol. instead of "phyto-template". NTs-MIP beads were subjected to "phyto-template" extraction by washing with $30 \mathrm{~mL}$ of $1 \mathrm{M} \mathrm{NaOH}$ solution, followed by two times washing with $30 \mathrm{~mL}$ of $0.1 \mathrm{~N} \mathrm{HCl}$. All supernatants were analyzed by HPLC-UV to confirm a $98 \%$ extraction efficiency. The beads were washed with $50 \mathrm{~mL}$ water per gram of sample in order to remove 
the $\mathrm{NaCl}$ crystals which were formed on the surface of beads. All the extraction procedures lasted $4 \mathrm{~h}$ at room temperature and the polymers were finally dried for $48 \mathrm{~h}$ under vacuum at $80^{\circ} \mathrm{C}$.

Table 1. Polymerization conditions for the NTs-MIPs

\begin{tabular}{|c|c|c|c|c|c|c|c|}
\hline \multirow[t]{2}{*}{ Polymer* } & \multicolumn{4}{|c|}{ Monomer (mmol) } & \multirow{2}{*}{$\begin{array}{l}\text { EDMA } \\
(\text { mmol) }\end{array}$} & \multirow{2}{*}{$\begin{array}{l}\text { Phyto-template*** } \\
\text { (mL) }\end{array}$} & \multirow{2}{*}{$\begin{array}{r}\text { AIBN } \\
(\mathbf{m m o l})\end{array}$} \\
\hline & $\mathbf{A A}$ & IA & МАA & HEMA & & & \\
\hline MIP AA & 7.3 & 0 & 0 & 0 & 26.5 & 6.5 & 1.2 \\
\hline MIP HEMA & 0 & 0 & 0 & 4.1 & 26.5 & 6.5 & 1.2 \\
\hline MIP IA-AA & 3.6 & 1.9 & 0 & 0 & 26.5 & 6.5 & 1.2 \\
\hline MIP IA-MAA & 0 & 1.9 & 2.9 & 0 & 26.5 & 6.5 & 1.2 \\
\hline MIP IA-HEMA & 0 & 1.9 & 0 & 2.1 & 26.5 & 6.5 & 1.2 \\
\hline
\end{tabular}

\section{Adsorption and selectivity trials}

To investigate the adsorption capacity of the beads, both MIP and NIP (30 mg) were placed in a 6 $\mathrm{mL}$ light-protected flasks and mixed with $3 \mathrm{~mL}$ of phyto-extract properly diluted in the $10^{-4}-10^{-5} \mathrm{~mol} / \mathrm{L}$ range, containing a known concentration of NTs. After $24 \mathrm{~h}$ at $25{ }^{\circ} \mathrm{C}$, the supernatant was analysed. Due to the fact that $\mathrm{H}$ and $\mathrm{PH}$ adsorb light in the same wavelength proximity $(593 \mathrm{~nm})$, the supernatant were analyzed by HPLC- DAD at $590 \mathrm{~nm}$. Specific parameters of MIPs (i.e. adsorption capacity, $Q$; imprinting factor, $F$; distribution coefficient, $K_{d}$; selectivity coefficient, $k$ and relative selectivity coefficient, $\left.k^{\prime}\right)$ were calculated according to equations 1-5.

$$
\begin{aligned}
& Q=\left(c_{i}-c_{f}\right) \cdot V_{S} / m_{p} \\
& F=Q_{M I P} / Q_{N I P} \\
& k_{C 1-C 2}=K_{d, C 1} / K_{d, C 2} \\
& K_{d}=\left(c_{i}-c_{f}\right) \cdot V_{S} / c_{i} \cdot m_{p} \\
& k_{C 1}{ }^{\prime}=k_{C 1-C 2, M I P} / k_{C 1-C 2, N I P}
\end{aligned}
$$

Adsorption capacities of MIPs and their corresponding NIPs, $Q$ (g compound/g beads), were calculated using eq $(1)$, where $c_{i}(\mathrm{~g} / \mathrm{L})$ and $c_{f}(\mathrm{~g} / \mathrm{L})$ represents the initial and final concentrations of the compound (either $\mathrm{H}, \mathrm{PH}$, Proto-H and Proto- $\mathrm{PH}$ ) in the feed solution, $m_{p}(\mathrm{~g})$ is the amount of polymer beads taken into account and $V_{S}(\mathrm{~L})$ is the volume of the feed solution.

The imprinting factor, $F$, evaluates the imprinting effect; it can be expressed as the ratio between the binding concentration of the MIP and that of the NIP (eq (2)). The selectivity coefficient, $k$, eq (3) measures the affinity of MIPs for the targeted compound, $C 1$ against competitor species, $C 2$; and the distribution coefficient $K_{d C n}(\mathrm{~mL} / \mathrm{g})$ expressed in eq (4), represents the amount of compound $C n$ bounded per gram of beads relative to the amount of the same compound remaining in $1 \mathrm{~mL}$ of feed extract. Finally, the relative selectivity coefficient, $k$ ' (eq (5)), quantified the selectivity of the MIPs for targeted species against competitor species, but relative to the corresponding NIPs.

\section{Results and discussions}

\section{Characterization of MIPs and NIPs \\ FTIR Analysis}

To characterize the polymers and more specifically the template extraction step performed with $\mathrm{NaOH}$ and $\mathrm{HCl}$ for MIPs, the MIPs before and after template removal (noted MIP-Ex) and NIPs were 
analyzed by FTIR spectroscopy. As shown in Figure 1, characteristic bands of the polymer matrix were easily found in all spectra as follows: the $v_{\mathrm{C}-\mathrm{H}}$ (of the polymer backbone) appeared between 2890 $2995 \mathrm{~cm}^{-1}$ and the characteristic vibrations of the carboxyl functionality as $v_{-} \mathrm{OH}$ and $v_{-} \mathrm{C}=\mathrm{O}$ bands (from AA, MAA, IA and HEMA monomers) appeared between $3400-3700 \mathrm{~cm}^{-1}$ (unassociated hydroxyl) and $1725-1731 \mathrm{~cm}^{-1}$ wavelength, respectively. It can be observed that all spectra show similarities because the structures differ only in terms of functional groups of monomers and interactions established with the template. For example, the characteristic carboxyl bands $\left(v_{-} \mathrm{C}=\mathrm{O}\right.$ and $\left.v_{-} \mathrm{OH}\right)$ were shifted towards higher wave number values, in the MIP AA spectrum at 1734 and $3449 \mathrm{~cm}^{-1}$ (Figure $1 \mathrm{a}$ ); this behavior indicated stronger interactions of carboxyl groups with the NTs template. In addition, the specific bands of poly(EDMA) backbone were observed in all spectra: the typical and intense $\mathrm{C}=\mathrm{O}$ and $\mathrm{C}-\mathrm{O}$ ester stretching bands at $1727 \mathrm{~cm}^{-1}$ and $1158 \mathrm{~cm}^{-1}$, respectively. The $-\mathrm{OCH}_{2}$ deformation vibration band from EDMA was also present between 1458-1460 $\mathrm{cm}^{-1}$. The spectra of MIPs before NTs removal (Fig. $1 \mathrm{a}-\mathrm{e})$ revealed the presence of two characteristic bands for the quinoid form of NTs, one at around $1560 \mathrm{~cm}^{-1}\left(v_{-\mathrm{C}=\mathrm{O}}, v_{-\mathrm{C}=\mathrm{C}}\right)$ and the other at around $843 \mathrm{~cm}^{-1}\left(v_{-\mathrm{C}-\mathrm{O}}, v_{\mathrm{Ar}-\mathrm{OH}}\right)$. These bands were assigned to the aromatic rings of $\mathrm{H}, \mathrm{PH}$ and precursors [20]. The extraction of NTs from the MIPs was confirmed by the absence of any major characteristic band of NTs in the MIP-Ex spectra and by the high similitude between the spectra of MIPs and that of corresponding NIPs.

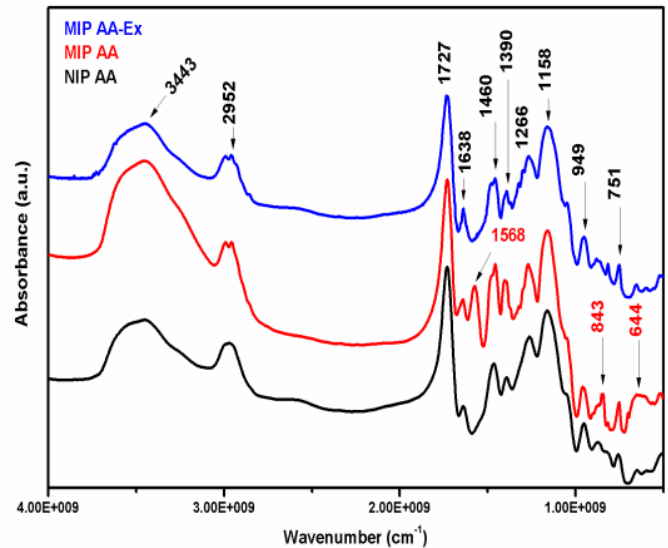

(a)

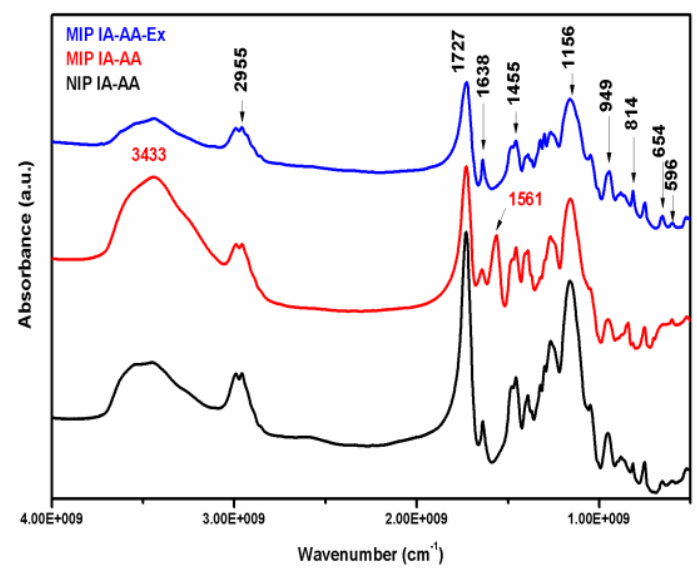

(c)

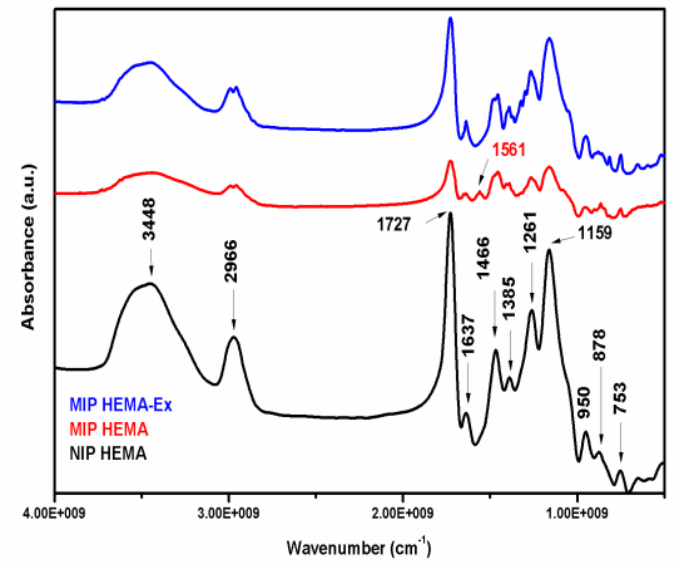

(b)

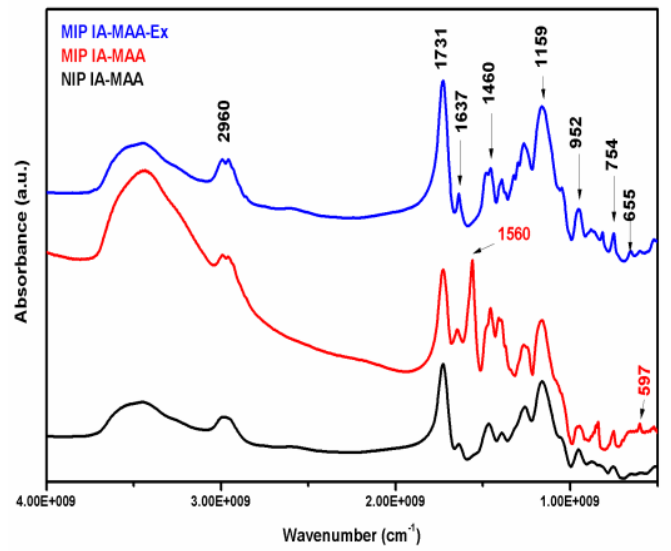

(d) 


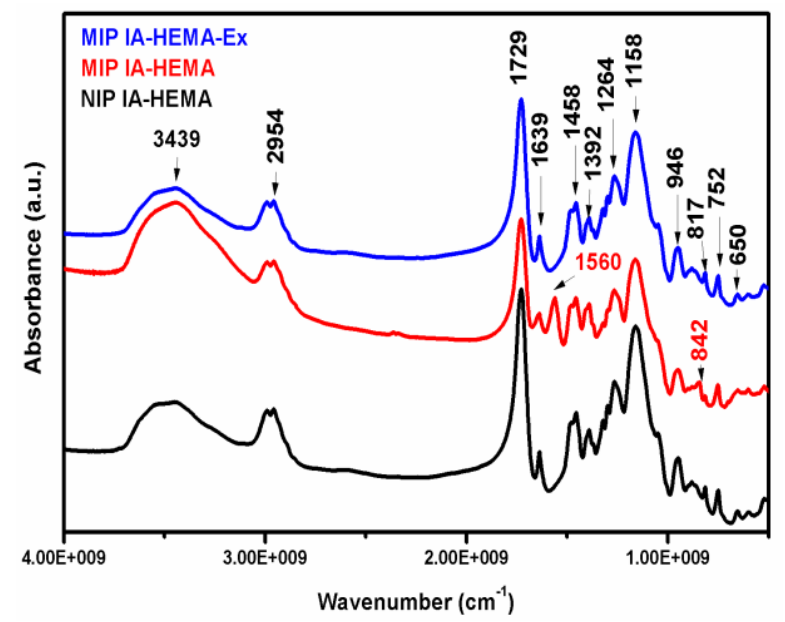

Figure 1. FTIR spectra of (a) MIP AA, (b) MIP HEMA, (c) MIP IA-AA, (d) MIP IA-MAA and (e) MIP IA-HEMA before and after NTs extraction, compared to their non-imprinted homologues NIPs

\section{SEM Analysis}

The morphology of the imprinted, non-imprinted and extracted beads was assessed by scanning electron microscopy (SEM). For instance, figure 2 shows SEM scans of the AA-based beads from which it is possible to observe the morphology of MIP AA after "phyto-template" extraction by washing with $1 \mathrm{M} \mathrm{NaOH}$ solution, followed by two times washing with $0.1 \mathrm{~N} \mathrm{HCl}$ that led to the formation of $\mathrm{NaCl}$ crystals on the surface of particles (Figure $2 \mathrm{c}$ and $\mathrm{d}$ ). To remove the salt crystals, the beads were vigorously washed with water (Figure 2e and f). MIP AA beads exhibited a more defined porous structure than that of the NIP AA (Figure $2 g$ and $h$ ). The use of HEMA alone and IA copolymers with HEMA, AA and MAA led to similar morphological properties of beads (Figure 3). It is also important to mention that ethanol contained in the NTs "phyto-template" extract and the saline saturated media worked in tandem for creating hollow morphologies (Figure 3a). The most probable mechanism for creating the hollows refers to "extrusion" of polymer from the core towards the surface. Proof of this polymer extrusion lies on the surface of un-washed beads which were decorated with agglomerated polymer nanoparticles (Figure $2 \mathrm{~b}$ and c). Together with this polymer extrusion, opened interconnected macropores are formed (such as pore channels that link the core with the surface of beads). Hence, the MIP beads described in this paper exhibited similar and reproducible physicalchemical characteristics, as obtained in the previous study reported by our group [23]. All beads were spherical, with sizes varying from 15 to $120 \mu \mathrm{m}$.

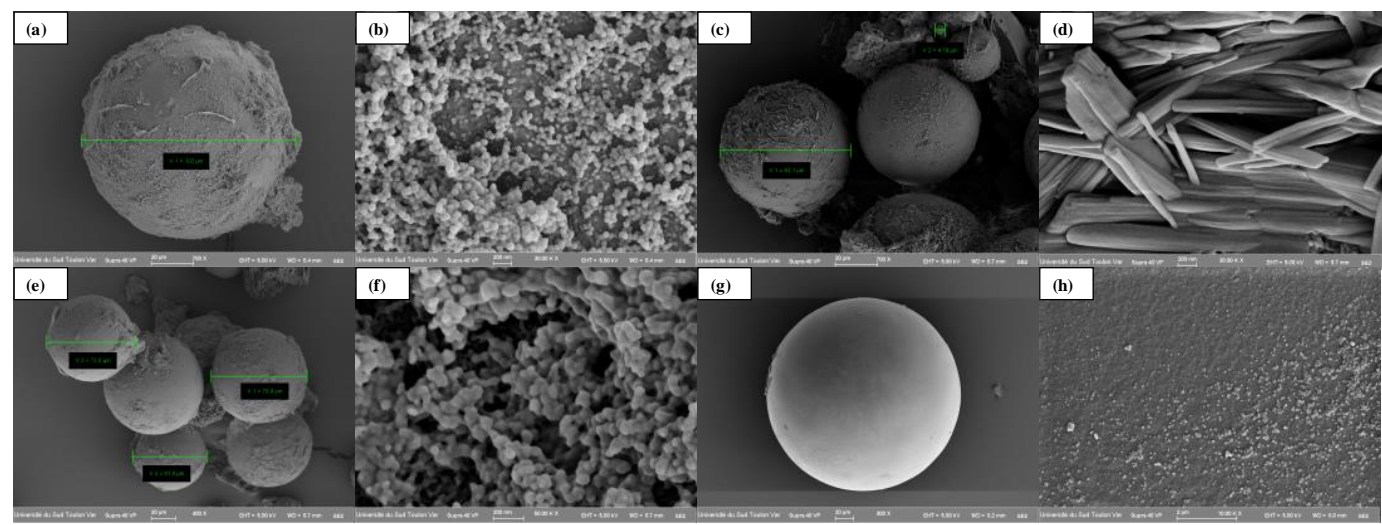

Figure 2. SEM pictures of MIP AA before (a,b) $[20 \mu \mathrm{m}, 200 \mathrm{~nm}]$ and after NTs extraction (c,d) [20 $\mu \mathrm{m}, 200 \mathrm{~nm}]$, after washing with water (e,f) $[20 \mu \mathrm{m}, 200 \mathrm{~nm}]$ and of NIP AA (g,h) $[20 \mu \mathrm{m}, 2 \mu \mathrm{m}]$ 

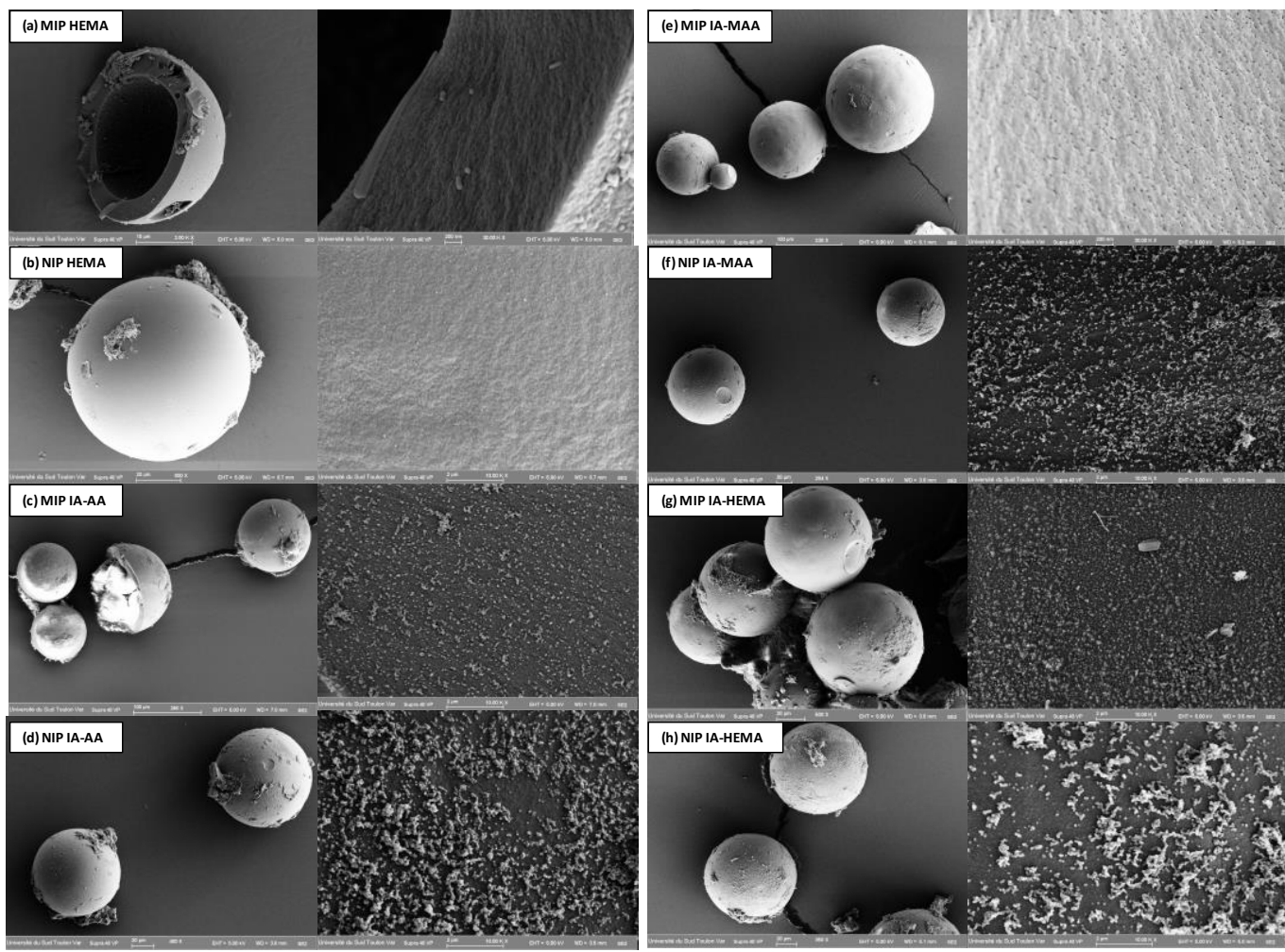

Figure 3. SEM pictures of (a) MIP HEMA [10 $\mu \mathrm{m}, 200 \mathrm{~nm}$ ], (b) NIP HEMA [20 $\mu \mathrm{m}, 2 \mu \mathrm{m}$ ],

(c) MIP IA-AA [100 $\mu \mathrm{m}, 2 \mu \mathrm{m}$ ], (d) NIP IA-AA [20 $\mu \mathrm{m}, 2 \mu \mathrm{m}$ ], (e) MIP IA-MAA

[100 $\mu \mathrm{m}, 200 \mathrm{~nm}]$, (f) NIP IA-MAA [20 $\mu \mathrm{m}, 2 \mu \mathrm{m}$ ], (g) MIP IA-HEMA [200 $\mu \mathrm{m}, 2 \mu \mathrm{m}$ ],

\section{Thermal Analysis (TGA)}

(h) NIP IA-HEMA [20 $\mu \mathrm{m}, 2 \mu \mathrm{m}]$

Thermal stability of MIPs and NIPs obtained by suspension polymerization was investigated by thermogravimetric analysis (TGA/DTG). By comparing the degradation of MIPs before and after NTs extraction to that of corresponding NIPs, similar thermal behaviors were observed (Figure 4). Decomposition of the cross-linked polymers occurred in three main steps. The mass losses were above $80 \%$ at $700{ }^{\circ} \mathrm{C}$. Lower mass losses for the extracted MIPs were registered in all cases compared to their corresponding NIPs.

The DTG curves also showed three separate degradation steps. Within a temperature range of 20$140{ }^{\circ} \mathrm{C}$, physisorbed water is released and intermolecular dehydration takes place. Thereafter, within a temperature range of $140-250{ }^{\circ} \mathrm{C}$ a first decarboxylation step is observed for the systems with IA; this being a dicarboxylic acid which release $\mathrm{CO}_{2}$ for steric stability. The main thermal decomposition of all MIPs starts at around $260{ }^{\circ} \mathrm{C}$ and around $220{ }^{\circ} \mathrm{C}$ for the NIPs, respectively; this indicating higher thermal stability for the MIPs. During the last decomposition step, polymer chains degrade together with (i) decarboxylation of AA at around $400{ }^{\circ} \mathrm{C}$ (Figure 4a), (ii) ester formation for IA-AA (Figure 4c) and IA-MAA (Figure 4e) at around $320^{\circ} \mathrm{C}$, (iii) ester formation for IA-HEMA (Figure 4d) at around $360{ }^{\circ} \mathrm{C}$; (iv) random chain scission of HEMA at $350{ }^{\circ} \mathrm{C}$ (Figure 4b) [27], and, finally, (iv) main backbone degradation starting at around $410{ }^{\circ} \mathrm{C}$. Nevertheless, AA and IA-AA-based copolymers have better thermal stability in the $20-400{ }^{\circ} \mathrm{C}$ temperature range compared to HEMA and IA-HEMAbased copolymer, which is probably due to their higher effective cross-link density and, thus, homogeneity.

The results reveal a higher thermal stability of the MIP beads before NTs extraction, due to strong template-polymer interactions. For instance, this fact is confirmed by the disappearance of some shoulders appearing between $300-320{ }^{\circ} \mathrm{C}$ for the extracted MIPs (except for HEMA-based polymers). 


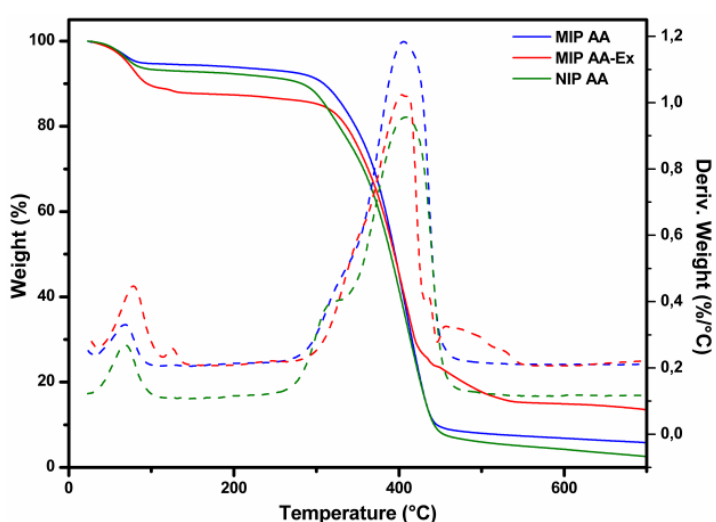

(a)

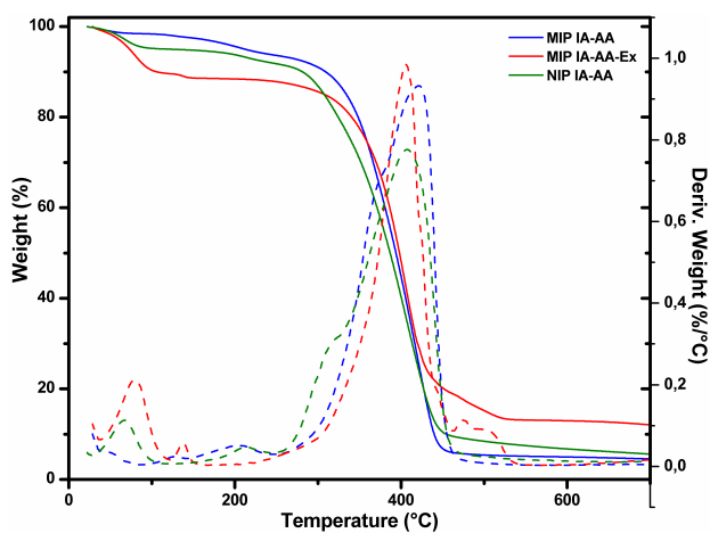

(c)

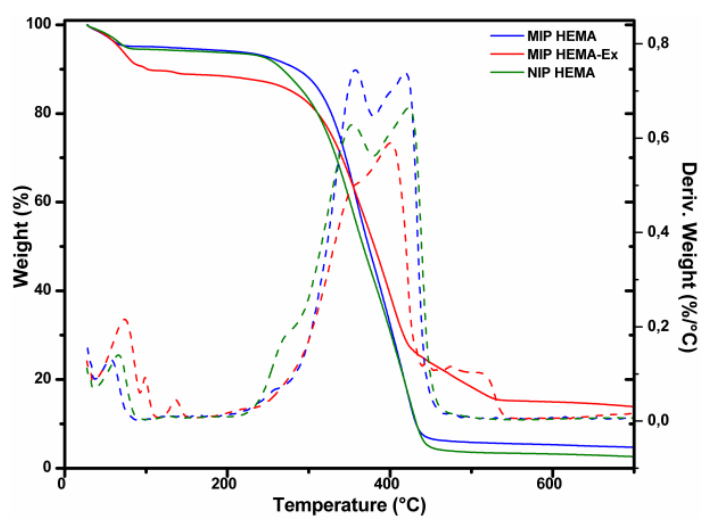

(b)

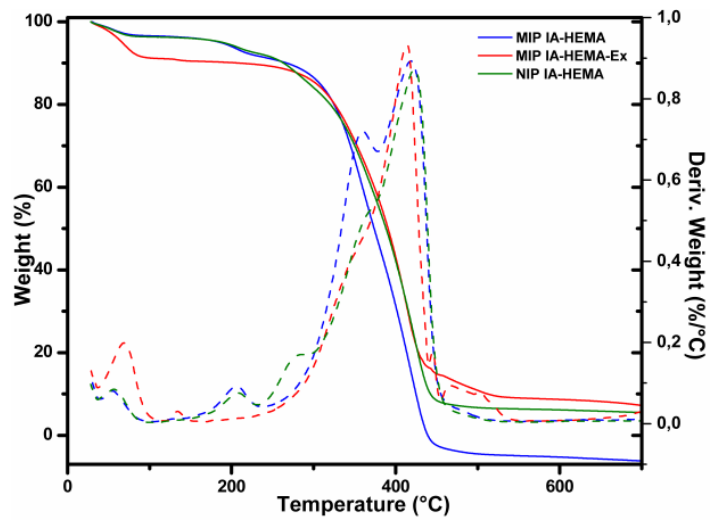

(d)

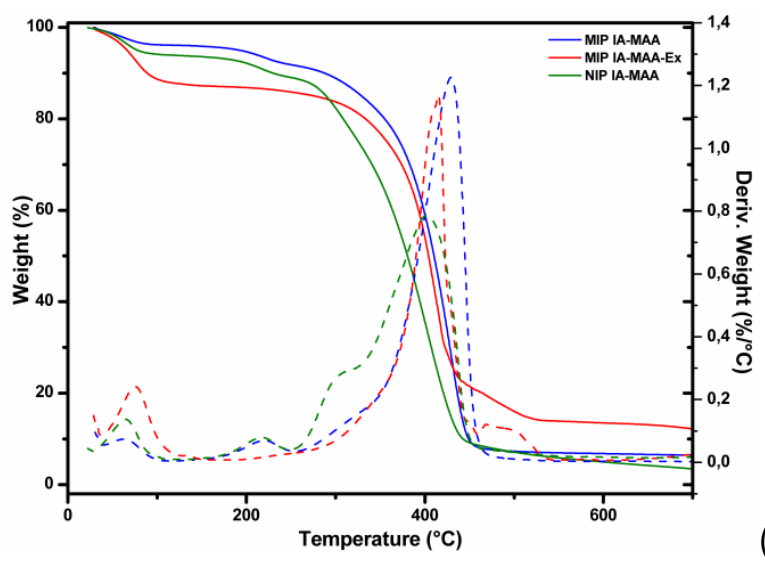

(e)

Figure 4. TGA and DTG curves for (a) MIP AA (b) MIP HEMA (c) MIP IA-AA (d) MIP IA-HEMA (e) MIP IA-MAA before and after NTs extraction, compared to their non-imprinted homologues NIPs

\section{Re-binding and selectivity experiments in batch mode}

NIP and extracted MIP beads were tested for NTs up-take using the same "phyto-extract" of 0.029 wt.\% NTs used for imprinting, diluted in the proper range with $\mathrm{EtOH} / \mathrm{H}_{2} \mathrm{O}$, to highlight NTs imprinting effect upon MIPs recognition ability. Data collected from the affinity and selectivity experiments in aqueous solutions for both MIP and NIP, regarding the adsorption capacities are given in Figure 5 ( $\mathrm{a}$ and $\mathrm{b}$ ). As expected, MIP beads presented higher affinity towards NTs than the corresponding NIPs, showing the contribution of the specific sites generated during molecular imprinting. 
The value of adsorption capacity $Q$, quantifies the amount of NTs retained by a gram of polymer at a given initial concentration and time (here after $24 \mathrm{~h}$ ). From Figure 5, it can be seen that MIP IA-AA was by far the most promising MIP system. High adsorption capacities were registered for this system, i.e. $334 \mu \mathrm{g} \mathrm{g}^{-1}$ for PH (and $137 \mu \mathrm{g} \mathrm{g}^{-1}$ for NIP) and $186 \mu \mathrm{g} \mathrm{g}^{-1}$ for $\mathrm{H}$ (90 $\mu \mathrm{g} \mathrm{g}^{-1}$ for NIP) (Figure $5 \mathrm{a}$ ). Although the up-take capacities for proto-PH and proto-H were 5 times lower (due the very low amounts in the initial extract), it can be seen that MIP IA-AA exhibited strong affinity towards the two precursors (Figure 5b). The adsorption capacities of MIP IA-AA towards proto-H and proto-PH were the highest from the series of the 5 MIPs $\left(27 \mu \mathrm{g} \mathrm{g}^{-1}\right.$ and $74 \mu \mathrm{g} \mathrm{g}^{-1}$, respectively).
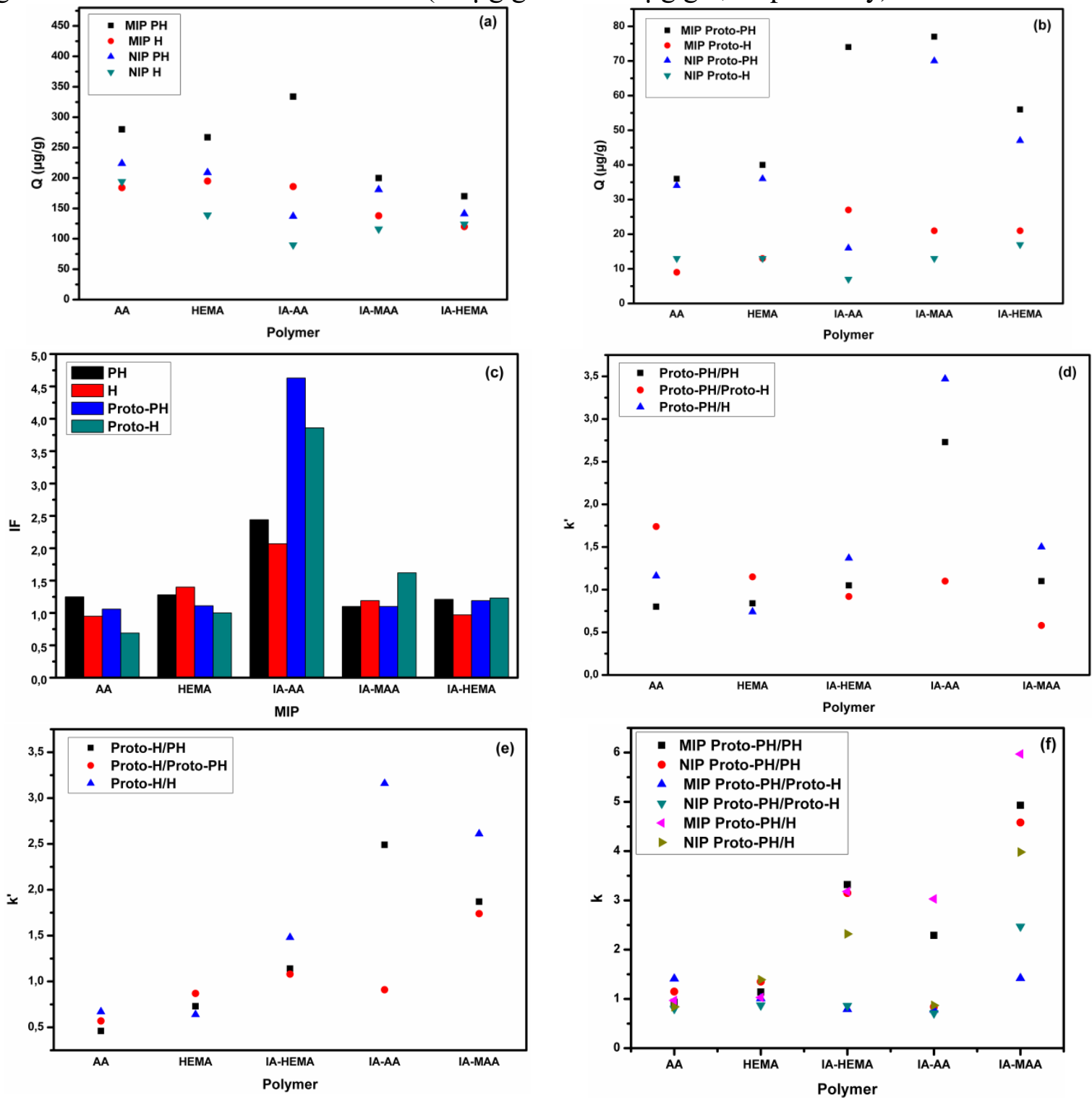

Figure 5. Variation of specific parameters in batch rebinding of $\mathrm{H}$ and $\mathrm{PH}$ from extracts with 0.029 wt.\% NTs, relative to the initial beads composition: (a) Adsorption capacities, Q of MIPs and NIPs for

PH and $\mathrm{H}$ (b) Adsorption capacities, Q of MIPs and NIPs for Proto-PH and Proto-H (c) Bar chart showing results of imprinting factors, IF, for $\mathrm{PH}, \mathrm{H}$, Proto-PH and Proto-H (d) Relative selectivity coefficient, k' of MIPs for competitive adsorption of Proto-PH against $\mathrm{PH}$, Proto- $\mathrm{H}$ and $\mathrm{H}$, respectively (e) Relative selectivity coefficient, k' of MIPs for competitive adsorption of Proto-H against PH, Proto-PH and H, respectively (f) Selectivity coefficient, k of MIPs and NIPs for competitive adsorption of Proto-PH against $\mathrm{PH}$, Proto- $\mathrm{H}$ and $\mathrm{H}$, respectively (g) Selectivity coefficient, $\mathrm{k}$ of MIPs and NIPs for competitive adsorption of Proto-H against $\mathrm{PH}$, Proto-PH and $\mathrm{H}$, respectively. 
Further on, Figure 5 (c) shows that the highest imprinting factors, $I F$ were registered for the same MIP AA-IA system (meaning $\mathrm{IF}_{\text {Proto-PH }}=4.63, \mathrm{IF}_{\mathrm{PH}}=2.44, \mathrm{IF}_{\text {Proto-H }}=3.86$ and $\mathrm{IF}_{\mathrm{H}}=2.07$ ). These results indicated that the MIPs adsorbs proto-H and proto-PH in lower amounts but with higher specificity than PH and $\mathrm{H}$. In addition, the IF value of MIP IA-AA towards Proto-H in this work was much higher than that reported for the MIPs prepared by surface molecular imprinting techniques (meaning 3.86 compared to 2.88 [24] and 3.07 [25])

In order to examine the selectivity of the MIPs, the cross-reactivity of the four competitors Proto$\mathrm{H}, \mathrm{H}$, Proto-PH and $\mathrm{PH}$ was evaluated. Hence, competitive adsorption was quantified by calculating the distribution and the selectivity coefficients, $\mathrm{K}_{\mathrm{d}}$ and $\mathrm{k}$, as summarized in Table 2. Based on the values of $\mathrm{K}_{\mathrm{d}}$, the selectivity coefficients $\mathrm{k}$ ranged from 0.93 to 4.58 for MIPs. The $\mathrm{k}$ values are the highest for the MIP IA-MAA as it adsorbs about 5 times more selectively Proto-PH than PH and 4 times more selectively Proto- $\mathrm{H}$ than $\mathrm{H}$. Yet, the selectivity coefficients are not very far from the ones obtained for the control sample NIP (relative selectivity coefficients, k', Figure $5 \mathrm{~d}$ and e), which, is in agreement to the IF obtained for this MIP/NIP system. The high values are also the result of a very high affinity of the polymer matrix itself towards NTs. The following notable values of selectivity coefficients were found for the MIP IA-AA system, which compared to the NIPs (relative selectivity coefficients, k', Figure $5 \mathrm{~d}$ and e), it can be stated that is more selective for proto-H and proto-PH.

Furthermore, a preferential adsorption for proto-PH vs. proto-H was noticed. As also observed in the former experiments with $\mathrm{PH}$ vs. $\mathrm{H}$, this behavior is related to the concentration of the two compounds in the template extract. The efficiency of MIP IA-AA system can be explained by the fact that the two involved monomers (one carboxylic acid and one dicarboxylic acid) are more prone to establish strong hydrogen interactions with the templates due to multiple carboxyl groups. Overall, imprinting studies results showed the efficiency of the imprinting procedure and also the possibility of enhancing the specificity and selectivity of the matrix towards Proto- $\mathrm{H}$ and Proto-PH by tuning the monomer composition.

Table 2. The values of distribution coefficients $(\mathrm{mL} / \mathrm{g})$ and selectivity coefficients for $\mathrm{PH}, \mathrm{H}$, Proto-PH AND Proto-H

\begin{tabular}{|c|c|c|c|c|c|c|c|c|c|c|}
\hline \multirow[t]{2}{*}{ Polymer } & \multicolumn{4}{|c|}{ Kd } & \multicolumn{3}{|c|}{$\mathbf{k}_{\mathbf{P H}}$} & \multicolumn{3}{|c|}{$\mathbf{k}_{\mathbf{H}}$} \\
\hline & Proto-PH & PH & Proto-H & $\mathbf{H}$ & Proto-PH & Proto-H & $\mathbf{H}$ & PH & Proto-PH & Proto-H \\
\hline NIP AA & 30.90 & 26.85 & 38.23 & 36.95 & 0.87 & 0.70 & 0.73 & 1.38 & 1.19 & 0.97 \\
\hline MIP AA & 33.33 & 35.98 & 23.68 & 34.39 & 1.08 & 1.52 & 1.05 & 0.96 & 1.03 & 1.45 \\
\hline NIP HEMA & 33.33 & 24.61 & 38.23 & 23.96 & 0.74 & 0.64 & 1.03 & 0.97 & 0.72 & 0.63 \\
\hline MIP HEMA & 38.46 & 33.75 & 38.23 & 37.21 & 0.88 & 0.88 & 0.91 & 1.10 & 0.98 & 0.98 \\
\hline NIP IA-HEMA & 48.45 & 15.37 & 56.66 & 20.84 & 0.32 & 0.27 & 0.74 & 1.36 & 0.43 & 0.37 \\
\hline MIP IA-HEMA & 63.63 & 19.14 & 80.76 & 20.03 & 0.3 & 0.24 & 0.95 & 1.05 & 0.32 & 0.25 \\
\hline NIP IA-AA & 12.5 & 14.87 & 17.5 & 14.30 & 1.19 & 0.85 & 1.04 & 0.96 & 1.14 & 0.82 \\
\hline MIP IA-AA & 105.71 & 46.13 & 135 & 34.89 & 0.44 & 0.34 & 1.32 & 0.76 & 0.33 & 0.26 \\
\hline NIP IA-MAA & 94.59 & 20.63 & 38.23 & 23.75 & 0.22 & 0.54 & 0.87 & 1.15 & 0.25 & 0.62 \\
\hline MIP IA-MAA & 114.92 & 23.31 & 80.76 & 19.23 & 0.20 & 0.29 & 1.22 & 0.83 & 0.17 & 0.24 \\
\hline
\end{tabular}

\section{Conclusions}

This study depicted the influence of different monomers (AA, HEMA, IA, MAA and their combination) on the properties of MIP hollow beads for the efficient retention of proto-hypericin and proto-pseudohypericin, the biosynthetic precursors of hypericin and pseudohypericin found in $H$. Perforatum L. extracts. Five MIP systems were successfully prepared via suspension polymerization techniques using EDMA as cross-linker. The morphology, structure and thermal stability of the resulting MIPs and NIPs were characterized using SEM, FTIR and TGA. After evaluating the influence of different polymer systems upon the specificity and selectivity for NTs recognition, it was concluded that the highest adsorption capacities (Q), imprinting factor (IF) and relative selectivity coefficients (k') can be attributed to the MIP IA-AA system, which was more specific for Proto-H and Proto-PH. Overall, the proposed one-step polymerization method was inexpensive and allowed for a rapid optimisation of the MIP system able to retain the very low amounts of Proto-H and Proto-PH 
more specifically compared to the other two predominant NTs (hypericin and pseudohypericin) present in the H. Perforatum L. extract.

Acknowledgments: The authors thank for the help and support of the Romanian Ministry of Research and Innovation (MCI) and the Executive Unit for Financing Higher Education, Research, Development and Innovation (UEFISCDI) through Projects NUCLEU PN.19.23.02.01 and Project No. 71/2017, COFUND-M-ERA.NET II-TANDEM.

\section{References}

1. ***St. John's Wort. European Pharmacopoeia 9.0. Council of Europe, 2017: 1526- 1527.

2. FRANKLIN, G., BEERHUES, L., CELLAROVA, E., Frontiers in Plant Science 7, 2016, p. 1687.

3. ZIRAK, N., SHAFIEE, M., SOLTANI, G., MIRZAEI, M., SAHEBKAR, A., J. Cell. Physiol. 234 no. 6, 2019, p. 8496-8508.

4. MARRELLI, M., STATTI, G., CONFORTI, F., MENICHINI, F., Mini Rev. Med. Chem. 16, 2016, p. 710-720.

5. WÖLFLE, U., SEELINGER, G., SCHEMPP, CM., Planta Med, 80, 2014, p. 109-20.

6. SADDIQE, Z., NAEEM, I., MAIMOONA, A., J. Ethnopharmacol. 131, 2010, p. 511-521.

7. HUDSON, J.B., HARRIS, L., TOWERS, G.H.N., Antiviral Research, 20, 1993, p. 173-178.

8. ZHANG, W., LAWA, R. E., HINTONA, D. R., SU, Y., COULDWELLA, W. T., Cancer Letters, 96, no. 1, 1995, p. 31-35.

9. MIRMALEK, S.A., AZIZI, M.A., JANGHOLI, E., YADOLLAH-DAMAVANDI, S., JAVIDI, M.A., PARSA, Y., PARSA, T., SALIMI-TABATABAEE, S.A., KOLAGAR, H.G., ALIZADEHNAVAEI, R., Cancer Cell International, 16, 2016, no. 3.

10. MILEVSKAYA, V.V. et al., J. Anal. Chem., 71, 2016, p. 741- 747.

11. AGAPOUDA, A., BOOKER, A., KISS, T., HOHMANN, J., HEINRICH, M., CSUPOR, D., J. Pharm. Pharmacol., 71, 2019, pp. 15-37.

12. CAI, F., LI, Y., ZHANG, M., ZHANG, H., WANG, Y., HU, P., J. Sep. Sci., 38, 2015, p. 25882596.

13. SMELCEROVIC, A., LAATSCH, H., LEPOJEVIC, Z., DJORDJEVIC, S., Pharmazie 57, 2002, p. 178-180.

14. SARBU, A., IORDACHE, T.V., FLOREA, A.-M., Molecularly Imprinted Polymers (MIPs) Challenges, Uses and Prospects, 3, Nova Publishers, QUINN, T., New York, 2017, p. 119.

15. BELBRUNO, J.J., Chem. Rev. 119, no. 1, 2019, p. 94-119.

16. LI, Z., QIN, C., LI, D., HOU, Y., LI, S., SUN, J., J. Pharm. Biomed. Anal. 98, 2014, p. 210-220.

17. LAZAU, C., IORDACHE, T.-V., FLOREA, A.-M., ORHA, C., BANDAS, C., RADU, A.-L., SARBU, A., T. ROTARIU, Appl. Surface Sci., 384, 2016, p. 449-458.

18. AHMAD, O.S., BEDWELL, T.S., ESEN, C., GARCIA-CRUZ, A., PILETSKY, S.A., Trends Biotechnol., 37, no.3, 2019, p. 294-309

19. UDOMSAP, D., BRISSET, H., CUliOli, G., DOLlET, P., LAATIKAINEN, K., SIREN, H., BRANGER, C., Materials Today Communications 17, 2018, p. 458-465

20. FlOREA, A.-M., IORDACHE, T-V., BRANGER, C., GHIUREA, M., AVRAMESCU, S., HUBCA, G., SARBU, A., Talanta, 148, 2016, p. 37-45.

21. FLOREA, A.-M., IORDACHE, T-V., ZAHARIA, A., GEORGESCU, B., VOICU, A.E., TSYNTSARSKI, B., HUBCA, G., SARBU, A., Mater. Plast., 54, (3), 2017, 498.

22. VIVEIROS, R., REBOCHO, S., CASIMIRO, T., Polymers, 10, no. 3, 2018, p. 306.

23. FLOREA, A.-M., IORDACHE, T.-V., BRANGER, C., BRISSET, H., ZAHARIA, A., RADU, A.L., HUBCA, G., SARBU, A., Eur. Polymer J., 100, 2018, p. 48-56.

24. CHENG, W. X., FAN, F.F, ZHANG, Y., PEI, Z.C., WANG, W.J., PEI, Y.X., Polymers, 9, 2017, p. 135. 
25. PEI, Y.X., FAN, F.F, WANG, X.X., FENG, W.W., HOU, Y., PEI, Z.C., Polymers, 9, 2017, p. 469.

26. GAVRILA, A.-M., IORDACHE, T.-V., SANDU, T., ZAHARIA, A., RADU, A.-L., BRANGER, C., BRISSET, H., STOICA, E.B., APOSTOL, S., SARBU, A., Mater. Plast., 56, (2), 2019, 315

27. ÇAYKARA, T., OZYUREK, C., KANTOGlU, O., J. Appl. Pol. Science, 103, 2007, p. 16021607.

$\overline{\text { Manuscript received: } 16.03 .2020}$ 